SILVA, R. - A invenção da modernidade literária

\title{
A invenção da modernidade literária
}

[The invention of literary modernity]

http://dx.doi.org/10.11606/1982-88372237401

\section{Rafael Guimarães Tavares da Silva ${ }^{1}$}

Resenha de: MEDEIROS, Constantino Luz de. A invenção da modernidade literária: Friedrich Schlegel e o romantismo alemão. 1. ed. São Paulo: Editora lluminuras, 2018.

Friedrich Schlegel, um dos nomes principais do Primeiro Romantismo Alemão [Frühromantik], não é uma figura muito conhecida do público brasileiro, apesar de seu nome vir sempre citado - junto ao de seu irmão, August - por grandes manuais que destacam a importância de sua atividade literária e filológica. Esse desconhecimento deve-se, sem dúvida, em parte, à dificuldade de seus escritos, acusados em sua própria época de serem ininteligíveis, e à complexidade de suas referências filosófico-literárias. Em parte, contudo, esse desconhecimento se deve também à pequena quantidade de traduções para o português de sua vastíssima obra (em alemão). Desde as importantes traduções e pesquisas de Márcio Suzuki, do qual cumpre destacar o livro O Dialeto dos Fragmentos (SCHLEGEL 1997), essa carência tem sido paulatinamente suprida, mas nunca antes de forma tão sistemática e dedicada como com os trabalhos recentes de Constantino Luz de Medeiros.

Verdadeiro defensor do espírito primeiro-romântico alemão entre nós, o pesquisador tem publicado inúmeros artigos dedicados a divulgar o tema e aprofundar suas pesquisas desde 2010. Em 2015, Medeiros lançou um estudo preliminar sobre Friedrich Schlegel seguido de uma tradução de seu texto Relato sobre as obras poéticas

\footnotetext{
${ }^{1}$ Universidade Federal de Minas Gerais, Av. Pres. Antônio Carlos, 6627, Pampulha, Belo Horizonte, 31270-901. E-mail: gts.rafa@ hotmail.com. ORCID: 0000-0002-8985-8315
}

\section{(cc) BY-NC}

Pandaemonium, São Paulo, v. 22, n. 37, mai.-ago. 2019, p. 401-407 
de Giovanni Boccaccio, como fruto de sua pesquisa de mestrado. No ano seguinte, veio a lume a tradução dos Fragmentos sobre poesia e literatura (1797-1803): seguido de Conversa sobre poesia (SCHLEGEL 2016), num trabalho de tradução conjunta com Márcio Suzuki. Pouco depois, publicou ainda a tradução de Sobre o estudo da poesia grega (SCHLEGEL 2018), precedido de uma interessante apresentação sobre "[o] antigo e o moderno em Friedrich Schlegel".

Na linha desse esforço deliberado de construção do conhecimento em torno de seu objeto de predileção, Medeiros publicou em livro - também em 2018 - o fruto de sua pesquisa de doutorado, A invenção da modernidade literária: Friedrich Schlegel e o romantismo alemão. A fim de sugerir a importância desse título no horizonte intelectual brasileiro, gostaria de propor breves considerações sobre seu itinerário argumentativo e os principais assuntos abordados por ele, não tanto para propor uma leitura crítica de matéria tão vasta no curto espaço de uma resenha, mas apenas para incentivar a leitura e a discussão de um tema incontornável para os estudos literários e filosóficos.

Medeiros abre o primeiro capítulo de seu livro com considerações que buscam fundamentar sua opção por dividi-lo em grandes seções dedicadas respectivamente à história, à crítica e à teoria, a partir dos escritos de Schlegel. Nas palavras do estudioso:

O que toma corpo no primeiro romantismo alemão é o processo de reconfiguração dos discursos da teoria, da crítica e da história da literatura. Esse processo acompanha o surgimento de obras que apontam para a própria constituição ou que refletem sobre o fazer artístico, como Lucinde (1799) e Conversa sobre a poesia (1800), de Friedrich Schlegel, exemplos de literatura que produz a própria teoria. (MEDEIROS 2018: 17-18).

Desenvolvendo sua argumentação segundo tal tripartição - cuja influência sobre os estudos literários posteriores é necessário destacar, na linha do que se pode constatar em escritos de autores tão diversos quanto Chklovski, Wellek, Todorov e Compagnon, por exemplo -, Medeiros aprofunda indicações sugeridas por Nancy e Lacoue-Labarthe (1978), ao demonstrar a importância tanto da literatura para a obra de Schlegel quanto de Schlegel para a literatura. Ao mesmo tempo, evita as armadilhas apontadas pelos ensaios de Beiser (2003) e Frank (2004), ao levar em conta a dimensão filosófica do pensamento desse autor para a interpretação de suas considerações sobre literatura, crítica e história.

Guiado por tais princípios, Medeiros (2018: 17-36) dedica a primeira parte de seu primeiro capítulo à biografia de Friedrich Schlegel, sobretudo naquilo que a mesma revela de fundamental para a constituição de seus escritos: em sua educação religiosa; em suas leituras de Herder, Winckelmann e Lessing; em sua troca epistolar com seu irmão, 
SILVA, R. - A invenção da modernidade literária

August; em suas amizades com Novalis, Fichte e Schelling, até a constituição da “constelação romântica", por volta de 1796, e sua posterior dissolução, poucos anos depois, em 1801. Essa introdução funciona muito bem como forma de apresentação da relação entre as vidas desses estudiosos e suas obras, cabendo destacar a coerência prático-teórica do grupo durante todo o tempo em que esteve junto. Tem-se uma ideia do que seriam suas reuniões a partir daquilo que Schlegel apresenta - sob pseudônimos - em sua Conversa sobre poesia, publicado em 1800.

Na sequência, Medeiros (2018: 37-55) dedica profundas considerações à resolução schlegeliana da antinomia entre antigos e modernos. Procedendo a uma leitura comparativa do texto de Schiller, Sobre poesia ingênua e sentimental, publicado pouco antes de Schlegel dar a lume o outro texto dessa leitura comparativa, Sobre o estudo da poesia grega, Medeiros indica em que pontos essas propostas convergem e a partir de onde elas passam a divergir, retomando e aprofundando pontos anteriormente defendidos por um estudo de Jauss (1974). Sugerindo que as noções schillerianas de ingênuo e sentimental não coincidem com o que Schlegel afirma sobre o objetivo e o interessante, o estudioso defende que subjaz às duas propostas o interesse de destacar as diferenças qualitativas entre modos praticamente opostos de se fazer poesia. Embora esses modos não sejam estritamente ligados a uma diferença entre poetas antigos e modernos - posto que alguns modernos apresentariam características ingênuas (para falar como Schiller) ou objetivas (para falar como Schlegel) -, haveria uma tendência geral que diferenciaria a poesia antiga da moderna. É interessante destacar, contudo, que, embora ambos os autores louvem a perfeição da poesia antiga, seus escritos mantêm certa abertura para uma compreensão positiva da moderna (MEDEIROS 2018: 45). No caso de Schlegel, é nesse sentido que se deve compreender o que ele virá a desenvolver sob o conceito de "poesia romântica, universal e progressiva", tal como proposto no célebre fragmento 116 da revista Athenäum.

Ainda no interior da seção dedicada à "História", Medeiros (2018: 57-70) indica os possíveis precursores do pensamento histórico que Schlegel desenvolverá em seus estudos literários: Vico, Herder e Winckelmann, além de Friedrich August Wolff e Christian Gottlob Heyne, cujo aporte filológico foi imprescindível para sua formação. Para isso, o autor leva adiante importantes sugestões avançadas por Isaiah Berlin (1982 e 2015), demonstrando de que modo as mesmas se aplicariam ao pensamento específico de Schlegel. Nesse sentido, chama atenção a amplitude das referências literárias que o 
estudioso veio a demonstrar em suas preleções sobre a literatura europeia (ministradas entre 1803-1804, em Paris, e 1812, em Viena): autores gregos e latinos antigos, cristãos, alemães, italianos, franceses, ocitânicos, ingleses, espanhóis e portugueses, entre outros, são citados, analisados e articulados, em leituras a partir de suas línguas originais, numa verdadeira demonstração virtuosística dos dotes intelectuais do estudioso.

A segunda seção do livro, dedicada à "Crítica", volta-se para a incontornável questão da Bildung [formação] romântica. Sugerindo a forma como uma crítica aos filisteus (isto é, aos pequenos burgueses cuja conduta se pautava apenas por um utilitarismo de base mecanicista) se concatenava nos escritos românticos - mesmo naqueles de caráter romanesco - a uma proposta de intervenção na sociedade, Medeiros (2018: 84) indica a concepção de intelectual defendida por autores como Schlegel e Novalis. Aprofundando os apontamentos de Radrizzani (1997), o autor argumenta que o diálogo com as ideias de Fichte é fundamental para seu entendimento de que a poesia em sua acepção romântica, isto é, como princípio de criação de toda a atividade artística em sua dimensão crítica - deveria se revelar um medium fundamental para que o poeta e o crítico pudessem conduzir seus contemporâneos ao absoluto.

Dentre os expedientes críticos disponíveis ao romântico a fim de cumprir sua destinação, cumpre destacar a ironia romântica, o chiste e a alegoria. Medeiros (2018: 91107) propõe uma clara distinção entre as diferentes modalidades de ironia: retórica, socrática e romântica. Dando exemplos do modo por que obras românticas se valem dessa última modalidade mais refinada de ironia, como por meio de intervenções autorais, gracejos sérios e comentários metalinguísticos, desestabilizando os mais básicos pressupostos comunicacionais e abrindo a possibilidade para certo dialogismo, o estudioso destaca a importância do recurso para o desenvolvimento do que veio a se firmar como a literatura moderna. Dentre os exemplos de autores aventados como praticantes dessa modalidade romântica de ironia estão Miguel de Cervantes, Laurence Sterne, Jean Paul e Machado de Assis.

Essa seção encerra-se com considerações sobre o procedimento crítico da "caracterização" [Charakeristik], tal como desenvolvido por Schlegel. Com o fim de “concretizar a máxima de que um texto crítico-literário deve ser ele mesmo uma obra de arte, isto é, um complemento de criação artística, tornando a poesia mais poética e a crítica ainda mais crítica" (MEDEIROS 2018: 109), Schlegel propõe uma série de textos de fino apuro literário - arrogando para si a distinção de um gênero desenvolvido na própria 
antiguidade, com os Caracteres de Teofrasto - sobre autores importantes, como Johann Wolfgang Goethe, Georg Forster, Giovanni Boccaccio e Gotthold Ephraim Lessing. Nesses textos, ressalta-se a singularidade [Eigentümlichkeit] do autor interpretado, a partir da qual se avançam juízos mais gerais sobre sua obra no interior da história literária (MedeIROs 2018: 116-117).

A terceira seção do livro, dedicada à "Teoria", começa com a explicitação de algo que já havia sido esboçado: o desenvolvimento do conceito de romântico desde seu uso na Antiguidade e na Idade Média até o sentido reivindicado pelos Frühromantiker e que passava a compreender "[a] aproximação entre antigo e moderno, filosofia e poesia, a mescla de temas e formas literárias, o entrecruzar de política e estética" (MEDEIROS 2018: 141). Em seguida, passa-se a uma elaboração do conceito de "poesia romântica, universal, progressiva", que, embora anteriormente mencionado, só nesse momento do livro pode receber um tratamento capaz de sugerir a profundidade de que a noção desfruta no pensamento de Schlegel: em seu recurso à ironia romântica, à combinação de diferentes gêneros literários, à mescla de elementos do fantástico (imaginação criativa), do mímico (representação objetiva do histórico) e do sentimental (reflexão do sujeito), além de um compromisso com a Bildung [formação] e com o desenvolvimento de uma nova mitologia, numa incompletude que se revela uma forma de abertura ao porvir (MEDEIROS 2018: 145-154).

Na sequência da argumentação, Medeiros (2018: 159-167) propõe uma revisão sobre a discussão em torno da "teoria do romance", concentrando-se nas implicações alemãs dessa questão, sobretudo a partir do surgimento do romance moderno burguês na Inglaterra do séc. XVIII. A essa concepção burguesa de romance parece se opor aquela que vem a ser delineada pelos Frühromantiker (de modo explícito sobretudo a partir da obra Conversa sobre poesia, de Schlegel), segundo a qual o romance seria a poesia romântica mais originária, cuja diferença em relação a outros gêneros residiria na capacidade de constituir uma mistura de todas as formas literárias, mesclando em suas determinações o lírico, o épico e o dramático (MEDEIROs 2018: 167). Em sua dimensão dialógica e aberta, essa concepção de romance preconizaria a quebra da linearidade narrativa e dos critérios miméticos de representação da realidade (segundo os critérios aristotélicos da verossimilhança e da causalidade), em prol da possibilidade de se recorrer ao sentimental e ao fantástico (no limite, ao grotesco). Schlegel teria levado a cabo essas ideias em seu livro Lucinde, publicado em 1799, causando um verdadeiro choque no 
público, devido à matéria e à estrutura de sua narrativa (FIRCHOW 1971). Não há espaço para apreciar aqui o grau de novidade e riqueza desse livro, mas gostaria de deixar registrada a necessidade de que seja publicada o quanto antes uma tradução do mesmo para que também o público brasileiro possa apreciá-lo.

Encaminhando a conclusão de seu livro, Medeiros (2018: 183) avança algumas considerações sobre o importante uso que o fragmento vem a encontrar entre os românticos:

A característica dialógica do fragmento realça a crença na sociabilidade e no poder da criatividade artística que o primeiro romantismo alemão tem como uma de suas ideias centrais. O fragmento romântico não representa uma parte que se descolou ou quebrou do todo, um Bruchstück, mas um pedaço autônomo do todo (autônomo, porém, organicamente relacionado ao todo), criado intencionalmente de modo a deixar em aberto sua resolução. (MEDEIROS 2018: 183).

Ainda que reconheça suas afinidades com uma tradição iniciada com autores franceses - como Montaigne, Pascal e Chamfort - e presente já num alemão como Herder, Medeiros (2018: 183-194) destaca de que modo o fragmento adquire um estatuto central na obra de Schlegel, na medida em que combina uma série de pontos fundamentais de seu pensamento: a temática da mediação entre finito e infinito, a concisão e capacidade de polêmica do Witz [chiste], a conciliação entre uma perspectiva não-sistemática e uma holística, além de uma abertura para certa urbanidade e dialogismo que é a base para as formas de sinfilosofia e simpoesia pregadas por Schlegel como aspectos da Bildung [formação] delineada por seu projeto. Nesse sentido, o fragmento pode ser lido como uma espécie de alegoria para o próprio Frühromantik, especialmente nas obras de Schlegel.

O livro A invenção da modernidade literária condensa o resultado de anos dedicados por Constantino Luz de Medeiros à pesquisa dos Frühromantiker, com ênfase nos escritos de Schlegel, e revela o grau de maturidade de seu pensamento sobre inúmeras questões fundamentais para os estudos literários. A importância que o mesmo há de desenvolver para a formação dos leitores brasileiros que se interessam pelas áreas de Letras, Filosofia e História ou, ainda, pelas Humanidades em geral, já pode ser entrevista pela própria formulação com que seu autor o conclui, ao afirmar o seguinte:

Através de seus ensaios, romances, cartas, novelas e fragmentos, os jovens do primeiro romantismo alemão concretizaram a máxima de Friedrich Schlegel de que era necessário realizar uma revolução estética nos estudos de literatura. Ao aproximar reciprocamente poesia e filosofia, crítica e criação literária, eles renovaram os discursos da literatura, inaugurando, assim, a modernidade literária. (MEDEIROS 2018: 194). 


\section{Referências bibliográficas}

BEISER, Frederick. The Romantic Imperative: The Concept of Early German Romanticism. Cambridge; London: Harvard University Press, 2003.

BERLIN, Isaiah. As raízes do romantismo. Trad. Isa Mara Lando. 1. ed. São Paulo: Três Estrelas, 2015. . Vico e Herder. Trad. Juan Antonio Gili Sobrinho. Brasília: Editora da UnB, 1982.

FIRCHOW, Peter. Lucinde and the Fragments. Minneapolis: University of Minnesota Press, 1971.

FRANK, Manfred. The Philosophical Foundations of Early German Romanticism. New York: State University of New York Press, 2004.

JAUSS, Hans Robert. Schlegels und Schillers Replik auf die 'Querelle des Ancients et des Modernes'. In: JAUSS, Hans Robert. Literaturgeschichte als Provokation. Frankfurt am Main: Suhrkamp, 1974.

MEDEIROS, Constantino Luz de. Friedrich Schlegel: "Relato sobre as obras poéticas de Giovanni Boccaccio": tradução e estudo preliminar. São Paulo: Humanitas; FAPESP, 2015. . A invenção da modernidade literária: Friedrich Schlegel e o romantismo alemão. 1. ed. São Paulo: Iluminuras; UFMG, 2018.

LaCoue-LABARTHe, Philippe; Nancy, Jean-Luc. L'Absolu littéraire: théorie de la littérature du romantisme allemand. Paris: Éditions du Seuil, 1978.

RADRIZZANI, Ives. Zur Geschichte der romantischen Ästhetik: Von Fichtes Transzendentalphilosophie zu Schlegels Transzendentalpoesie. In: SCHRADER, Wolfgang H. Fichte und die Romantik. Fichte-Studien. Band 12. Amsterdam: Rodopi, 1997.

SCHLEGEL, Friedrich. $O$ dialeto dos fragmentos. Tradução, apresentação e notas de Márcio Suzuki. São Paulo: Editora Iluminuras, 1997.

. Fragmentos sobre poesia e literatura (1797-1803): seguido de Conversa sobre poesia. Tradução e notas de Constantino Luz de Medeiros e Márcio Suzuki. 1. ed. São Paulo: Editora Unesp, 2016.

. Sobre o estudo da poesia grega. Tradução de Constantino Luz de Medeiros. 1. ed. São Paulo: Iluminuras, 2018. 